\title{
New Blue Light-Emitting Isocyanobiphenyl Based Fluorophores: Their solvatochromic and biolabeling properties
}

\author{
Miklós Nagy ${ }^{1}$, Dávid Rácz ${ }^{1}$, Sándor Lajos Kovács ${ }^{1}$, László Lázár ${ }^{1}$, Péter Pál Fehér ${ }^{2}$, Mihály \\ Purgel $^{2,3}$, Miklós Zsuga ${ }^{1}$, Sándor Kéki ${ }^{1}$ *
}

${ }^{1}$ Department of Applied Chemistry, ${ }^{2}$ Department of Physical Chemistry ${ }^{3}$ MTA-DE Homogeneous Catalysis and Reaction Mechanisms Research Group, University of Debrecen, H-4032 Debrecen, Hungary

* Corresponding author: keki.sandor@science.unideb.hu, fax: +36 52 518662; H-4032 Debrecen, HUNGARY

\begin{abstract}
The preparation and optical study of 4-amino-4'-isocyanobiphenyl (ICAB) and its mono-and dialkylated derivatives (monoMICAB and diMICAB) are reported. They were found to be effective blue light emitters with a solvatochromic range of $\Delta \lambda_{\max }=104 \mathrm{~nm}, 92 \mathrm{~nm}$ and $90 \mathrm{~nm}$, respectively. All three compounds turned out to be promising candidates in protein-labeling, yielding $\sim 70-190 \mathrm{x}$ increase in their fluorescence intensity when mixed with 10x molar excess of bovine serum albumin (BSA). The binding constants for the BSA-fluorophore complexes were found to be $\mathrm{K}_{\mathrm{ICAB}-\mathrm{BSA}}=3.8 \times 10^{4} \pm 5.7 \times 10^{3} \mathrm{M}^{-1}, \mathrm{~K}_{\text {monoMICAB-BSA }}=6.0 \times 10^{4} \pm 3.9 \times 10^{3} \mathrm{M}^{-1}$ and $\mathrm{K}_{\text {diMICAB-BSA }}=2.3 \times 10^{4} \pm 3.2 \times 10^{3} \mathrm{M}^{-1}$. Time resolved fluorescence measurements revealed a nearly uniform $\sim 2$ ns lifetime for all three BSA-complexed ICAB derivatives.
\end{abstract}

Keywords: Fluorescence, Isocyanobiphenyl, Solvatochromism, DFT, BSA

\section{Introduction}

Solvatochromic fluorescent dyes have attracted great attention from both theoretical and practical points of view. Unlike common fluorescent dyes the color of their emitted light is sensitive to the polarity of their environment [1-3]. Beneficially their optical properties are extremely dependent upon not only the bulk, but even their microenvironment, therefore they are particularly suitable for the use in fluorescent microscopy and other molecular imaging techniques to visually separate the different parts of biomolecules (e.g. cells, proteins, tissues, tumors) [4,5]. Based on their behavior they can be considered as smart materials and their field of application covers optical chemical sensors, molecular electronics, smart display 
technology, photovoltaics, optical nonlinear systems, etc. The field of application can be further extended by taking advantage of the phenomenon of fluorescence quenching, which offers an even more sensitive qualitative and quantitative analysis of appropriate quencher molecules [6], furthermore structural information can also be gained [7].

Solvatochromic fluorophores are generally bipolar molecules, having a donor (e.g. amino, hydroxyl) and an acceptor (e.g. carbonyl, sulphonyl) group on an aromatic core, resulting a charge transfer between them. This dipole moment increases upon excitation and due to the solvent rearrangement around the excited fluorophore, the energy of the excited state decreases altering the Stokes-shift of the emission. Larger difference in the dipole moments of the ground and excited states therefore results a more pronounced solvatochromic effect. One way to increase this dipole moment difference is obtained by elongating the dipole axis by using a larger aromatic core without altering the donor and the acceptor groups as Kucherak et al demonstrated by exchanging the naphthalene core of PRODAN [8] to fluorene [9]. The Stokes-shift of the resulting dye turned out to be almost twice than that of the original.

Solvatochromic dyes are perfect choice for labeling proteins, cells and other biomolecules. They can simply incorporate to a feasible site (binding sites, hydrophobic pockets) of the macromolecule $[8,10,11]$, or can be attached to a specific amino acid unit, like in the case of Acrylodan (the acryl derivative of PRODAN), which forms strong covalent bond with the free thiol group of cysteine [12,13]. The change in the emitted fluorescent light indicates the alteration of the environment around the fluorophore, which is helpful for monitoring conformational changes in labeled biological macromolecules, or to study protein binding sites. Bovine serum albumin (BSA) and human serum albumin (HSA) are good model proteins with well-known structure to test labeling capability of dyes, and are widely used for that reason.

Recently we reported the discovery of a new solvatochromic compound family based on 1amino-5-isocyanonaphthalene (ICAN), where the donor group is amino and the acceptor group is isonitrile [14]. Our aim was to replace the naphthalene ring of ICAN to biphenyl as a cheap and effective alternative to improve the solvatochromic properties. Benzidine $(4,4$ 'diaminobiphenyl) was selected as starting material because benzidine and its derivatives are widely used in the industry for the synthesis of dyes and pigments. In addition to its easy availability preliminary quantum chemical calculations showed a significantly increased dipole moment in the excited state compared to that of ICAN. 
Hereby we report the preparation and optical study of 4-amino-4'-isocyanobiphenyl (ICAB) and its mono-and dialkylated derivatives. In addition the applicability of the ICAB derivatives in the field of biolabeling using BSA as model protein is demonstrated.

\section{Experimental}

\subsection{Materials}

Acetone, chloroform, dichloromethane (DCM), ethyl acetate (EtOAc), hexane, toluene, (reagent grade, Molar Chemicals, Hungary) were purified by distillation. Acetonitrile $(\mathrm{MeCN})$, tetrahydrofuran (THF), methanol (MeOH), dimethyl formamide (DMF), dimethyl sulfoxide (DMSO), pyridine (HPLC grade, VWR, Germany), cyclohexane, 1,4-dioxane,4,4'diaminobiphenyl (reagent grade, Reanal, Hungary), methyl iodide (Sigma-Aldrich, Germany) were used without further purification. Bovine Serum Albumin (BSA, Cell Culture Grade, $\mathrm{pH}$ 7.0, Lyophilized Powder, GE Healthcare Life Sciences, USA) was used as received.

\subsection{Synthesis}

\subsubsection{4-amino-4'-isocyanobiphenyl (ICAB)}

A $48 \mathrm{ml} \mathrm{ACE} \mathrm{pressure} \mathrm{tube} \mathrm{was} \mathrm{charged} \mathrm{with} \mathrm{4,4'-diaminobiphenyl} \mathrm{(2.00} \mathrm{g,} 10.9 \mathrm{mmol})$ dissolved in chloroform $(15 \mathrm{ml})$ and with potassium hydroxide $(3.00 \mathrm{~g}, 53.5 \mathrm{mmol})$ dissolved in water $(10 \mathrm{ml})$ and vigorously stirred with a magnetic stirrer at $120{ }^{\circ} \mathrm{C}$ for 3 days. After cooling down, the organic phase was separated, washed with water 3 times, dried on anhydrous magnesium sulfate and the solvent was removed on a rotary evaporator. The crude product was purified on a column filled with normal-phase silica gel, using dichloromethane as eluent. Yield: $0.53 \mathrm{~g}, 25 \%$ (pale yellow powder).

${ }^{1} \mathrm{H}$ NMR $\left(360 \mathrm{MHz}, \mathrm{CDCl}_{3}\right) \delta=7.52(\mathrm{~d}, J=8.4 \mathrm{~Hz}, 2 \mathrm{H}), 7.38(\mathrm{~d}, J=8.4 \mathrm{~Hz}, 4 \mathrm{H}), 6.75(\mathrm{~d}, J$ $=8.4 \mathrm{~Hz}, 2 \mathrm{H}), 3.81(\mathrm{~s}, 2 \mathrm{H}) \mathrm{ppm}$.

${ }^{13} \mathrm{C}$ NMR $\left(95 \mathrm{MHz}, \mathrm{CDCl}_{3}\right) \delta=160.1\left(\mathrm{C}_{\mathrm{NC}}\right), 143.6\left(\mathrm{C}_{4,1^{\prime}}\right), 139.4\left(\mathrm{C}_{1}\right), 127.0\left(\mathrm{C}_{4^{\prime}}\right), 125.8\left(\mathrm{C}_{3^{\prime}}\right.$, $\left.5^{\prime}\right), 124.7\left(\mathrm{C}_{2^{\prime}, 6^{\prime}}\right), 124.5\left(\mathrm{C}_{3,5}\right), 113.6\left(\mathrm{C}_{2,6}\right) \mathrm{ppm}$.

ESI-TOF MS (m/z): calculated for $\mathrm{C}_{13} \mathrm{H}_{10} \mathrm{~N}_{2}$ : 195.092; found: $195.092\left([\mathrm{M}+\mathrm{H}]^{+}\right)$.

\subsubsection{4-N-methylamino-4'-isocyanobiphenyl (monoMICAB) and 4- $N, N$-dimethylamino-4'-} isocyanobiphenyl (diMICAB)

A $100 \mathrm{ml}$ round-bottom flask was charged with 4-amino-4'-isocyanobiphenyl $(0.200 \mathrm{~g}, 1.03$ mmol), methyl iodide (192 $\mu \mathrm{l}, 3.09 \mathrm{mmol})$, potassium hydroxide $(0.28 \mathrm{~g}, 5.00 \mathrm{mmol})$ dissolved in dry dimethyl formamide, and the reaction mixture was stirred with a magnetic 
stirrer for 4 days at room temperature. The solution was diluted with dichloromethane, and washed with brine 3 times. The organic phase was dried on anhydrous magnesium sulfate and the solvent was removed on a rotary evaporator. The crude product was purified on a column filled with normal-phase silica gel, using dichloromethane:hexane 1:1 (V/V) as eluent. Yield: $60 \mathrm{mg}$ monoMICAB (27\%) and $62 \mathrm{mg}$ diMICAB (28\%). Both were obtained as white powder.

monoMICAB: ${ }^{1} \mathrm{H}$ NMR $\left(360 \mathrm{MHz}, \mathrm{CDCl}_{3}\right) \delta=7.53(\mathrm{~d}, J=8.4 \mathrm{~Hz}, 2 \mathrm{H}), 7.42(\mathrm{~d}, J=8.4 \mathrm{~Hz}$, 2H),7.37 (d, $J=8.4 \mathrm{~Hz}, 2 \mathrm{H}), 6.67$ (d,J=8.4 Hz,2H), 3.89 (s, 1H), 2.88 (s, 3H).

${ }^{13} \mathrm{C} \mathrm{NMR}\left(91 \mathrm{MHz}, \mathrm{CDCl}_{3}\right) \delta=163.8\left(\mathrm{C}_{\mathrm{NC}}\right), 149.5\left(\mathrm{C}_{4,1^{\prime}}\right), 142.5\left(\mathrm{C}_{1}\right), 128.8\left(\mathrm{C}_{4^{\prime}}\right), 128.1\left(\mathrm{C}_{3^{\prime}, 5^{\prime}}\right)$, $127.8\left(\mathrm{C}_{2^{\prime}}\right), 126.9\left(\mathrm{C}_{6^{\prime}}\right), 126.6\left(\mathrm{C}_{3,5}\right), 112.7\left(\mathrm{C}_{2,6}\right), 30.6\left(\mathrm{C}_{\mathrm{Me}}\right)$.

ESI-TOF MS (m/z): calculated for $\mathrm{C}_{14} \mathrm{H}_{12} \mathrm{~N}_{2}$ : 209.107; found: $209.107\left([\mathrm{M}+\mathrm{H}]^{+}\right)$.

$\operatorname{diMICAB}:{ }^{1} \mathrm{H}$ NMR $\left(360 \mathrm{MHz}, \mathrm{CDCl}_{3}\right) \delta=7.57(\mathrm{~d}, J=8.6 \mathrm{~Hz}, 2 \mathrm{H}), 7.50(\mathrm{~d}, J=8.7 \mathrm{~Hz}, 2 \mathrm{H})$, $7.40(\mathrm{~d}, J=8.5 \mathrm{~Hz}, 2 \mathrm{H}), 6.82(\mathrm{~d}, J=8.8 \mathrm{~Hz}, 2 \mathrm{H}), 3.03(\mathrm{~s}, 6 \mathrm{H})$.

${ }^{13} \mathrm{C}$ NMR $\left(91 \mathrm{MHz}, \mathrm{CDCl}_{3}\right) \delta=163.8\left(\mathrm{C}_{\mathrm{NC}}\right), 150.5\left(\mathrm{C}_{4,1^{\prime}}\right), 142.4\left(\mathrm{C}_{1}\right), 127.85\left(\mathrm{C}_{3^{\prime}}, 5^{\prime}\right), 127.60$ $\left(\mathrm{C}_{2^{\prime}}\right), 126.86\left(\mathrm{C}_{6^{\prime}}\right), 126.59\left(\mathrm{C}_{3,5}\right), 125.83\left(\mathrm{C}_{4^{\prime}}\right), 112.61\left(\mathrm{C}_{2,6}\right), 40.37\left(\mathrm{C}_{\mathrm{Me}}\right)$.

ESI-TOF MS (m/z): calculated for $\mathrm{C}_{15} \mathrm{H}_{14} \mathrm{~N}_{2}$ : 223.123; found: $223.123\left([\mathrm{M}+\mathrm{H}]^{+}\right)$.

\section{Methods}

\section{1. $N M R$}

${ }^{1} \mathrm{H}$ and ${ }^{13} \mathrm{C}$-NMR spectra were recorded in $\mathrm{CDCl}_{3}$ at $25^{\circ} \mathrm{C}$ on a Bruker AM 360 spectrometer at $360 \mathrm{MHz}\left({ }^{1} \mathrm{H}\right)$ or $90 \mathrm{MHz}\left({ }^{13} \mathrm{C}\right)$ with tetramethylsilane as the internal standard.

\subsection{ESI-TOF MS}

ESI-TOF MS measurements were performed with a BioTOF II instrument (Bruker Daltonics, Billerica, MA). The concentration of the samples were $0.02 \mathrm{mg} / \mathrm{ml}$. The solutions were introduced directly into the ESI source with a syringe pump (Cole-Parmer Ins. Comp.) at a flow rate of $2 \mu \mathrm{L} / \mathrm{min}$. The temperature of the drying gas $\left(\mathrm{N}_{2}\right)$ was maintained at $100^{\circ} \mathrm{C}$. The voltages applied on the capillary entrance, and the second skimmer were $-4500 \mathrm{~V}$ and $30 \mathrm{~V}$, respectively.

\subsection{UV-vis}

The UV-vis spectra were recorded on a HP 8453 diode array spectrophotometer in a quartz cuvette of $1 \mathrm{~cm}$ optical length. For UV-vis measurements the investigated compounds were 
dissolved in the solvents at a concentration of $0.20 \mathrm{mg} / \mathrm{mL}$ and was diluted to $0.004 \mathrm{mg} / \mathrm{mL}$ and $0.0008 \mathrm{mg} / \mathrm{mL} .3 .00 \mathrm{ml}$ solution was prepared from the sample.

\subsection{Fluorescence measurements}

Steady-state fluorescence measurements were carried out using a Jasco FP-8200 fluorescence spectrophotometer equipped with a Xe lamp light source. The excitation and emission spectra were recorded at room temperature, using $2.5 \mathrm{~nm}$ excitation, $5.0 \mathrm{~nm}$ emission bandwith, and $200 \mathrm{~nm} / \mathrm{min}$ scanning speed. $3.00 \mathrm{ml}$ solution was prepared from the sample with a concentration of $0.0008 \mathrm{mg} / \mathrm{mL}$. Fluorescence quantum yields were calculated by using quinine sulfate in $0.1 \mathrm{~mol} / \mathrm{L}$ sulfuric acid as the reference absolute quantum efficiency $\left(\Phi_{\mathrm{n}}=\right.$ $55 \%)$.

Laser flash photolysis experiments have been carried out in an Applied Photophysics LKS.60 nanosecond transient absorption spectrometer, equipped with a Quantel Brilliant Nd:YAG laser along with its second and third harmonic generator. Third harmonic was used, which emits at $355 \mathrm{~nm}$.

\subsection{Determinations of the Binding Constants}

$1.373 \times 10^{-4} \mathrm{M}$ BSA stock solution was prepared in distilled water at $25{ }^{\circ} \mathrm{C}$. Proper amounts of the BSA stock solution were diluted to a final volume of $3 \mathrm{~mL}$. The concentration range of BSA was set between $\left(3.43 \times 10^{-6}-3.43 \times 10^{-5} \mathrm{M}\right)$ to be in $\sim 1-10$ molar equivalent range relative to the dyes. Next $10 \mu \mathrm{L}$ acetonitrile stock solution $(0.2 \mathrm{mg} / \mathrm{mL})$ of the dyes were added, were equilibrated for 15 minutes and their fluorescence spectra were recorded. The excitation wavelengths were $314 \mathrm{~nm}, 335 \mathrm{~nm}$ and $347 \mathrm{~nm}$ for ICAB, monoMICAB and diMICAB respectively. Using these wavelengths no excitation of the uncomplexed BSA could be observed. For the calculations the fluorescence intensities of the BSA-fluorophore complexes measured at the peak maximum were used. Assuming 1:1 complexation between the fluorophore (F) and the BSA (B) according to eq. 1.

$$
\mathrm{F}+\mathrm{B} \stackrel{\mathrm{K}}{\rightleftharpoons} \mathrm{FB}
$$

where FB is the fluorophore-BSA complex and $\mathrm{K}$ is the equilibrium constant.

$$
\mathrm{K}=\frac{[\mathrm{FB}]}{\left([\mathrm{F}]_{0}-[\mathrm{FB}]\right)\left([\mathrm{B}]_{\mathrm{o}}-[\mathrm{FB}]\right)}
$$


In the case of $[\mathrm{B}]_{\mathrm{o}}>>[\mathrm{FB}]$, eq. 2 reduces and $[\mathrm{FB}]$ can be expressed by eq. 3 .

$$
[\mathrm{FB}]=\frac{\mathrm{K}[\mathrm{F}]_{\mathrm{o}}[\mathrm{B}]_{\mathrm{O}}}{1+\mathrm{K}[\mathrm{B}]_{\mathrm{O}}}
$$

Assuming that the fluorescence intensity of FB is proportional to its concentration eq. 4 comes as:

$$
\mathrm{I}_{\mathrm{F}}=\frac{\varphi \mathrm{K}[\mathrm{F}]_{\mathrm{o}}[\mathrm{B}]_{\mathrm{o}}}{1+\mathrm{K}[\mathrm{B}]_{\mathrm{O}}}
$$

where $\varphi$ is the proportionality constant (i.e. instrumental constant)

Furthermore, using eq. 5 as a target function the binding constant (K) can be determined by parameter fitting from the experimental intensity versus BSA concentration plots.

$$
\mathrm{I}_{\mathrm{F}}=\frac{\mathrm{a}[\mathrm{B}]_{\mathrm{o}}}{1+\mathrm{b}[\mathrm{B}]_{\mathrm{o}}}
$$

where $\mathrm{a}=\varphi \mathrm{fK}[\mathrm{F}]_{\mathrm{o}}$ and $\mathrm{b}=\mathrm{K}$

For parameter fitting to the experimental data, a home-made computer program written in Turbo Pascal using the Gauss-Newton-Marquardt procedure was employed [15]. In addition, eq. 5 . can be linearized to obtain eq. 6 as:

$$
\frac{1}{\mathrm{I}_{\mathrm{F}}}=\frac{1}{\mathrm{a}} \frac{1}{[\mathrm{~B}]_{\mathrm{O}}}+\frac{\mathrm{b}}{\mathrm{a}}
$$

\subsection{Density Functional Theory (DFT) calculations}

The DFT and TDDFT calculations were carried out using the Gaussian 09 software package [22]. The M06 meta-hybrid GGA functional was used [16] together with TZVP basis set [17]. Geometry optimizations were carried out in both the ground and excited states using the polarizable continuum model (PCM) to account for solvent effects of DMSO [18,19]. For these calculations, Gaussian 09's default Integral Equation Formalism variant (IEFPCM) was used [20,21]. 


\section{Results and Discussion}

Our aim was to synthesize a novel family of fluorophores with enhanced solvatochromic properties by increasing the distance between the donor (amino) and the acceptor (isonitrile) groups, yielding an increased dipole moment of the molecule. 4-amino-4'-isocyanobiphenyl (ICAB) was obtained by the exchange of the naphthalene ring of ICAN to biphenyl. In order to further enhance the polarizability the amino group was mono- and dimethylated resulting 4N-methylamino- (monoMICAB) and 4-N,N-dimethylamino-4'-isocyanobiphenyl (diMICAB). 4,4'-diaminobiphenyl (benzidine) was selected as the starting material based on its easy availability, originating from the extensive use of this compound in commercial dyes. Throughout the paper benzidine is used as reference for the optical properties of its newly prepared isocyano-derivatives.

\subsection{Synthesis and optical properties}

Synthesis of 4-amino-4'-isocyanobiphenyl (ICAB) was performed according to the method presented in our previous work [14], with slight modifications as presented in Scheme 1. The purity of the products was confirmed by ${ }^{1} \mathrm{H}$ as well as ${ }^{13} \mathrm{C}$ NMR analysis, the resulting spectra are presented in the Supporting Information.
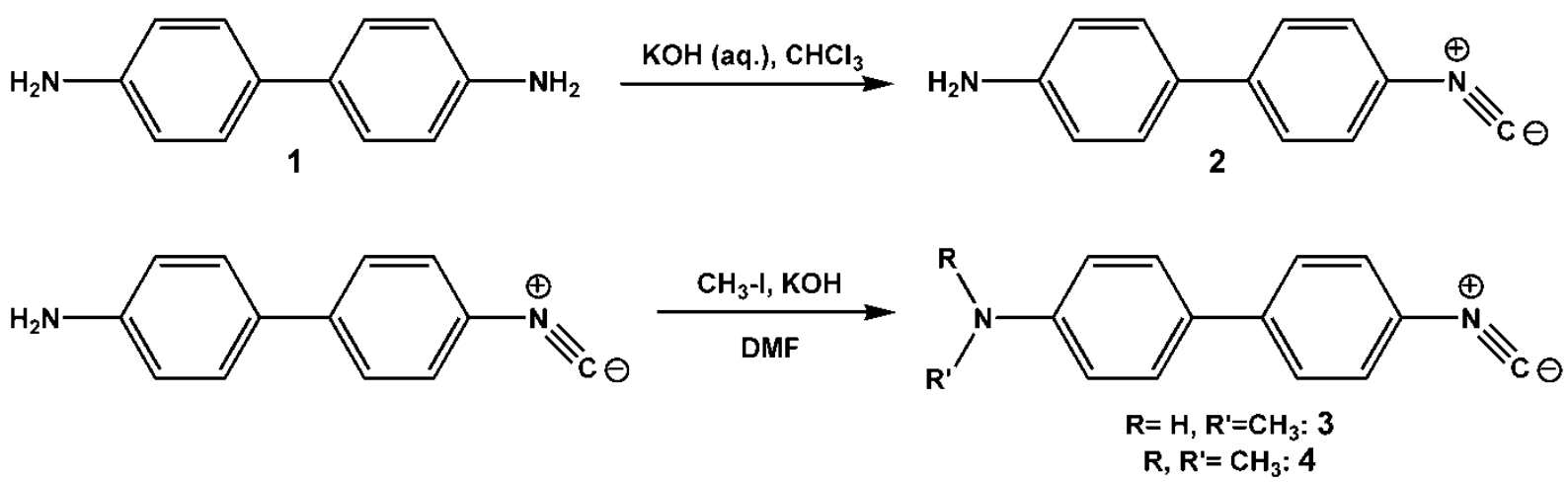

Scheme 1. Synthesis of 4-amino- (ICAB) 4-N-methylamino- (monoMICAB) and 4-N,Ndimethylamino-4'-isocyanobiphenyl (diMICAB)

UV-Vis absorption spectra were recorded in hexane for all products and benzidine as well (Figure S3 in the Supporting Information). The structures of the spectra are similar, they consist of a band with higher energy at $\lambda=200-250 \mathrm{~nm}$, attributed to the $\pi-\pi^{*}$ transition, and a broader one with lower intensity between $\lambda=250$ and $350 \mathrm{~nm}$ for the HOMO-LUMO transition, characteristic for the phenylene-based aromatic compounds. This lower energy part of the spectra are presented in Figure 1. The maximum of these low energy bands were used 
for excitation during the fluorometric measurements. It should be noted, that by incorporating the isonitrile group, the maximum of the band for the HOMO-LUMO transition was shifted from $\lambda_{\max }=279 \mathrm{~nm}$ (benzidine) to $\lambda_{\max }=301 \mathrm{~nm}$ in the case of ICAB, due to the charge separation present between the amino and the isonitrile group. This charge separation can be further increased by methylation of the amino group because of the electron donating property of the methyl groups, which further decreases the energy of the HOMO-LUMO transition, resulting a bathochromic shift, $12 \mathrm{~nm}$ for the monomethyl and an additional $10 \mathrm{~nm}$ for the dimethyl derivative. This higher wavelength for the excitation maximum is advantageous in practical applications.

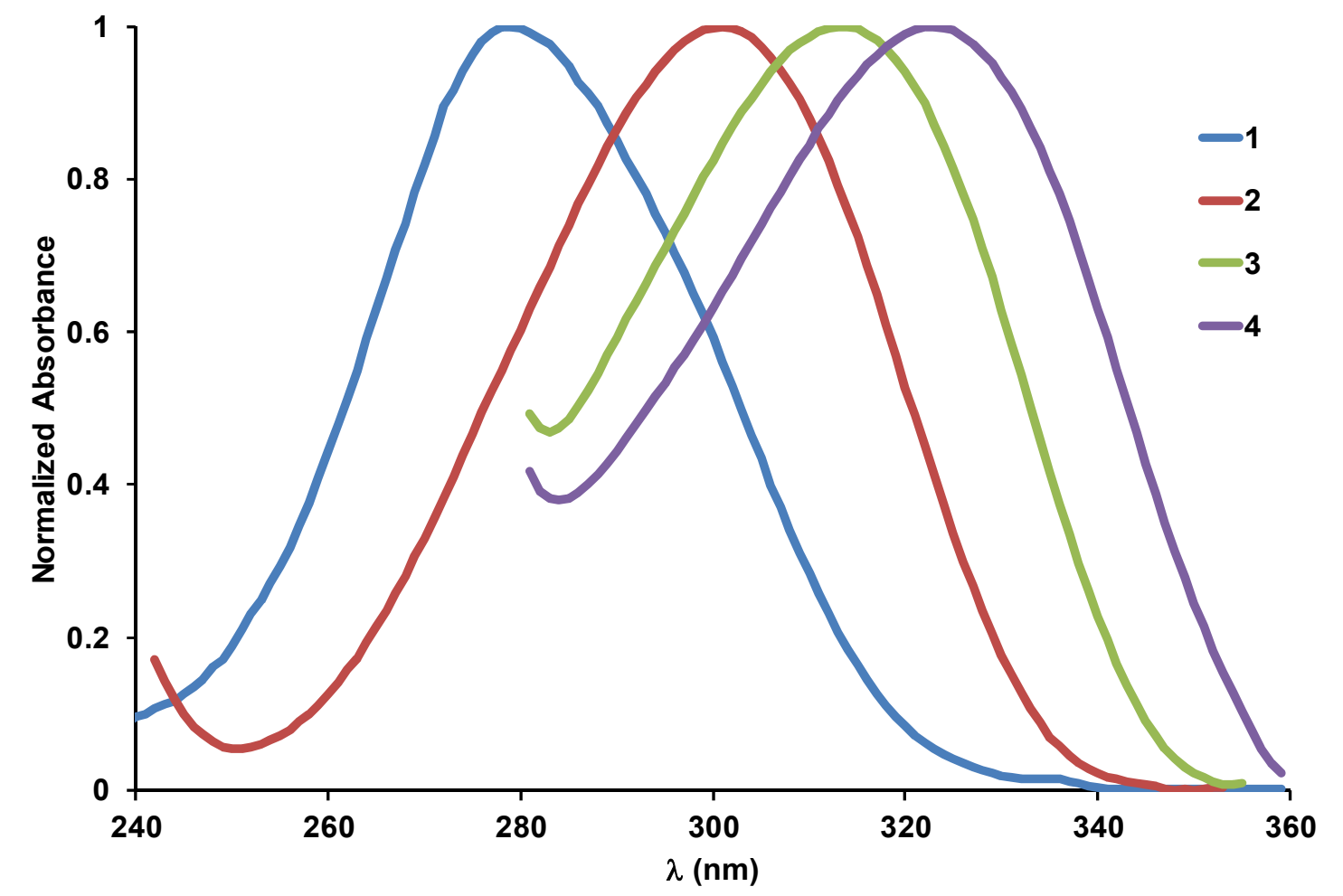

Figure 1. Normalized UV-Vis spectra of benzidine (1), ICAB (2), monoMICAB (3) and diMICAB (4) in hexane

Fluorescence measurements indicated that the absorbance and excitation spectra are identical (excitation spectra can be found in the Supporting Information in Figure S4). In different solvents the excitation maxima varied between $279-306 \mathrm{~nm}, 298-329 \mathrm{~nm}, 305-338 \mathrm{~nm}$ and 315-340 $\mathrm{nm}$ in the case of benzidine, ICAB, monoMICAB and diMICAB, respectively. The same bathochromic shift can be observed in the emission maxima as in the case of absorption maxima, due to the more pronounced charge separation. However, the excitation maxima show only a minor solvent-dependence, in the range of 25-33 $\mathrm{nm}$. 
More remarkable differences can be observed between the emission properties (Figure 2). Emission maxima of benzidine are all in the UV range $(372-403 \mathrm{~nm}$ in hexane and in DMSO, respectively). This range was significantly increased to $353-457 \mathrm{~nm}$ (hexane-water) due to the presence of the isonitrile group, which means a $\Delta \lambda=104 \mathrm{~nm}$ solvatochromic range.
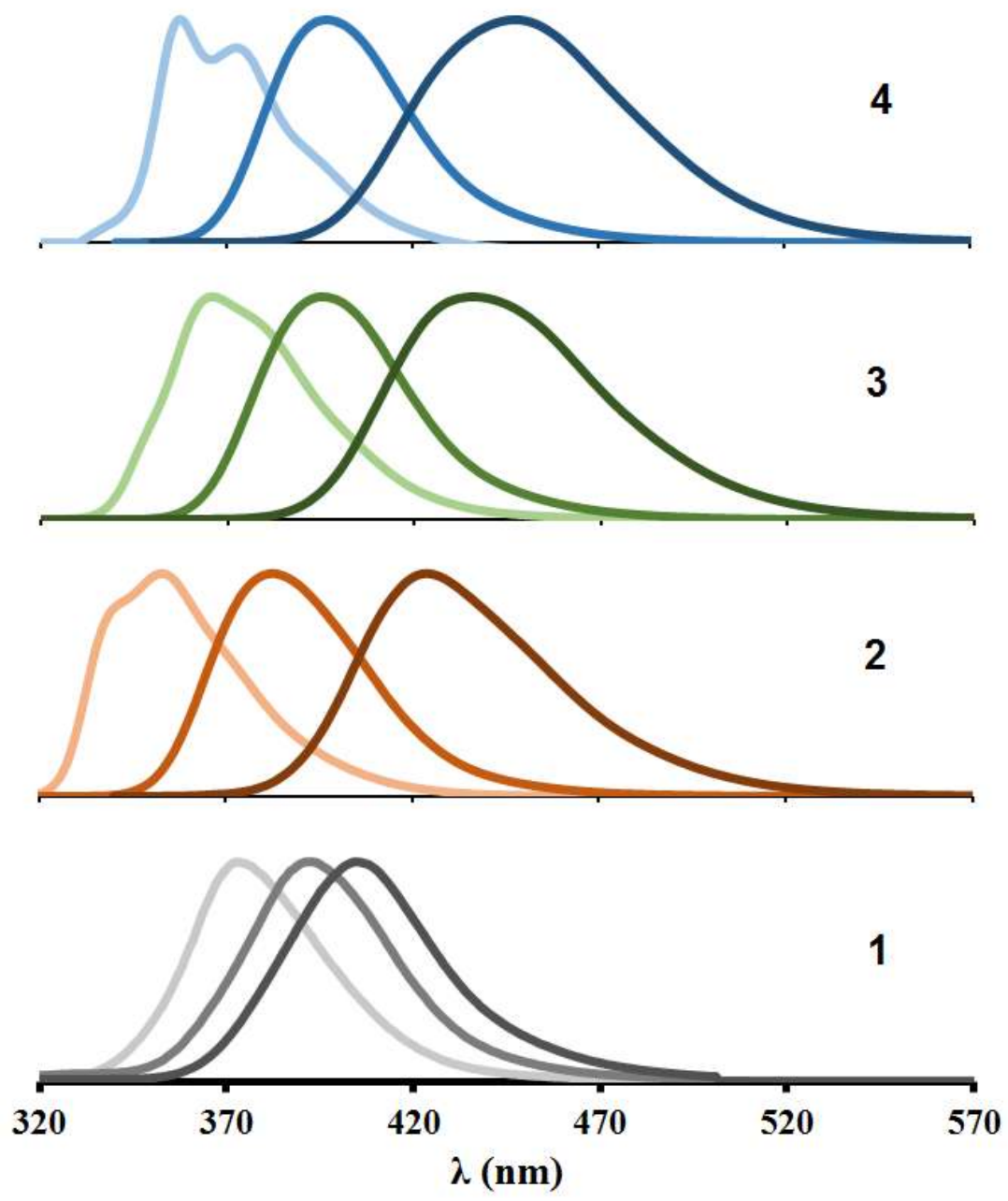

Figure 2. Normalized fluorescence emission spectra of benzidine (1), ICAB (2), monoMICAB (3) and diMICAB (4) in hexane, dioxane and DMSO (from left to right, $\left.20{ }^{\circ} \mathrm{C}, \mathrm{V}=3 \mathrm{~cm}^{3}, \mathrm{c}=4.12 \times 10^{-6} \mathrm{M}\right)$

Surprisingly, this shift decreased as consequence of the methylation of the amine group. In case of monoMICAB the shift was $\Delta \lambda=92 \mathrm{~nm}$ (366-458 nm, hexane-water), and for diMICAB it further decreased to $\Delta \lambda=90 \mathrm{~nm}(357-447 \mathrm{~nm}$, hexane-DMSO). Dimethylation would be expected to offer greater electron donation, but its resonance contribution is suppressed by an out-of-plane twist required to place the hydrogen at the peri-position of the fused ring, and the conformational constraints originating from dimethylation suppress delocalization of the nonbonding electrons on the amine nitrogen [23]. For diMICAB it is also striking, that the 
emission maximum with the highest wavelength belongs to the one in DMSO instead of water. It can be explained by the lack of the $\mathrm{NH}$ hydrogens, which prevents the interaction with water to improve solubility. Furthermore, poor solubility of the molecules can cause their association, providing a more nonpolar environment. Another interesting phenomenon can be observed on the spectra, that the emission peaks split in hexane, which is probably due to the $\mathrm{N}-\mathrm{H}$ or $\mathrm{N}-\mathrm{C}$ vibrational transitions. The spectral properties of the ICAB derivatives are summarized in Table 1.

Table 1. Emission $\left(\lambda_{\mathrm{em}}\right)$, excitation $\left(\lambda_{\mathrm{ex}}\right)$ maxima, Stokes shift $(\Delta v)$ and quantum yield $\left(\Phi_{\mathrm{F}}\right)$ of benzidine (1), ICAB (2), monoMICAB (3) and diMICAB (4) in different solvents.

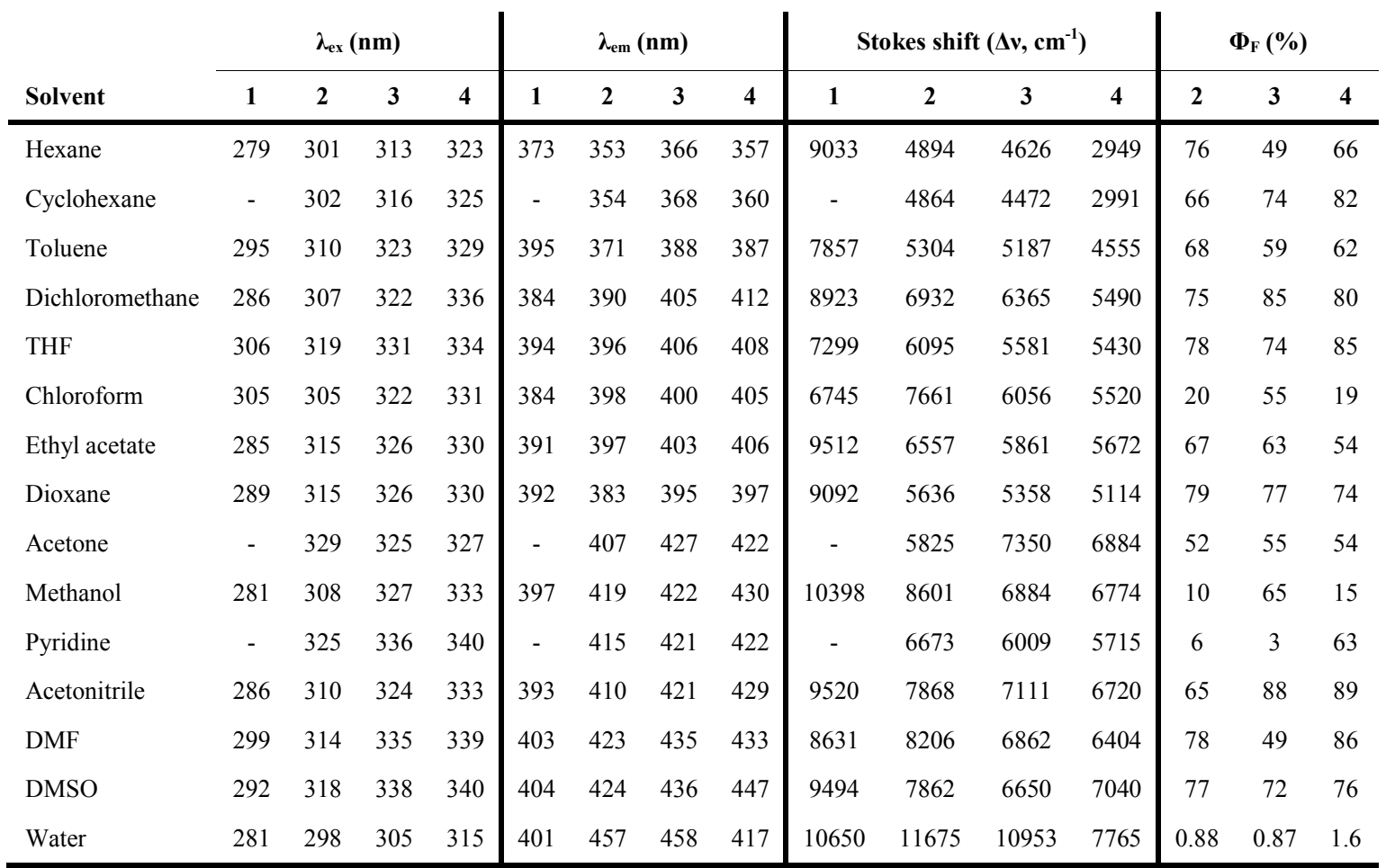

In acetone and pyridine it was not possible to determine the fluorescence parameters due to the excitation and emission at low wavelengths overlapped with those of the solvents. It can be concluded from the table, that the Stokes shifts increase with solvent polarity, however quantum yields do not seem to follow any trend. In water the fluorescence of all compounds are almost completely quenched which can be important for future applications such as biolabeling. 

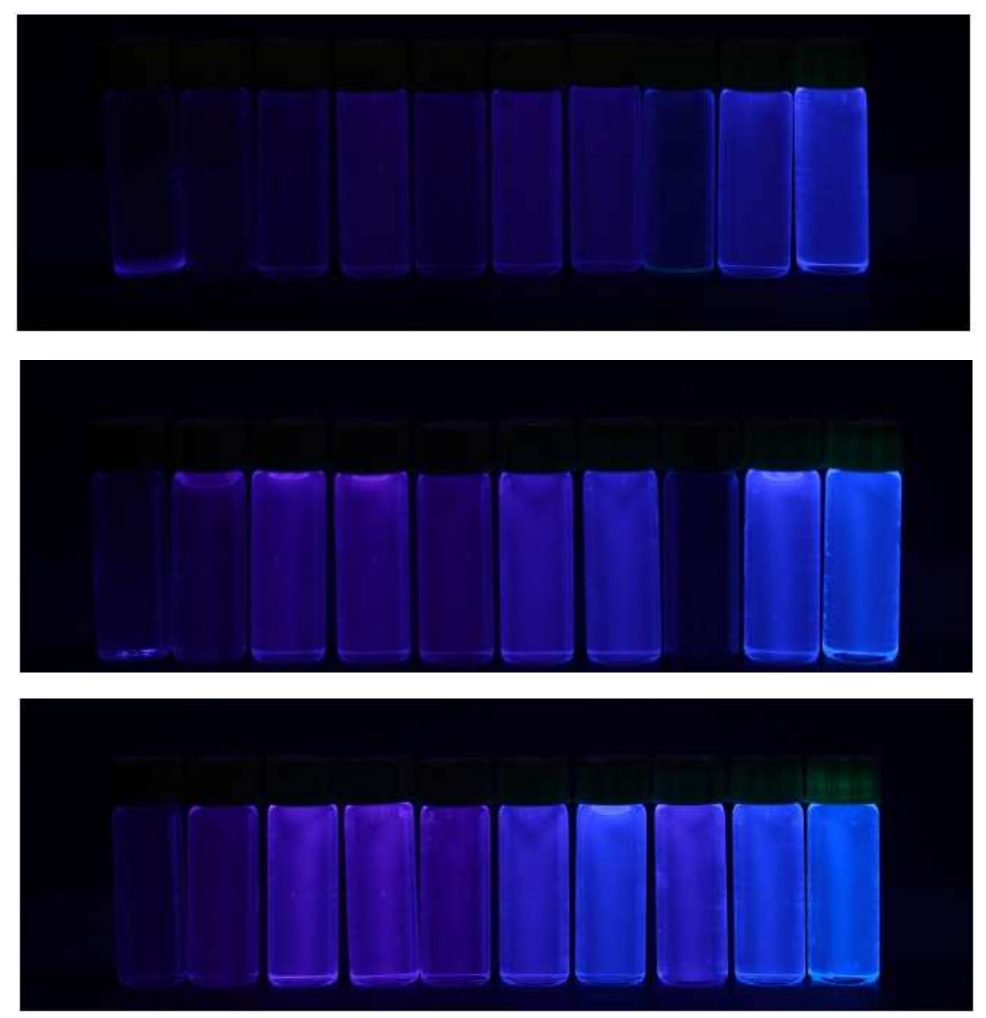

Figure 3. Visible fluorescence of ICAB (top), monoMICAB (middle) and diMICAB (bottom) in solvents with increasing polarity (hexane, toluene, dichloromethane, THF, 1,4-dioxane, acetone, acetonitrile, pyridine, DMF and DMSO) excited at $\lambda=365 \mathrm{~nm}$.

All solutions have the same concentration: $0.056 \mathrm{~g} / \mathrm{L}$

In Figure 3 it can be clearly seen that while ICAB has visible emission only in highly polar solvents (DMF, DMSO), monoMICAB has in half of the ones presented, and diMICAB has almost in all of them (except for the most nonpolar, hexane, and only with low intensity in toluene). It should be noted, however, that not only the position of the emission maxima, but the width and shape of the emission band have a great influence on the visible color as well. Pictures also well demonstrate the solvatochromic behavior, i.e. the bathochromic shift of the emitted light with increasing solvent polarity.

Another important phenomenon can be observed, quenching of the fluorescence in pyridine in the case of ICAB and monoMICAB, which can be explained by the formation of a hydrogenbonded complex between the free $\mathrm{N}-\mathrm{H}$ hydrogen on the fluorophore and a pyridine molecule, as it is discussed in details in the Supporting Information.

For the quantitative description of the solvent-dependent behavior of the solvatochromic fluorophores three models were applied. The Lippert-Mataga theory which only investigates 
the correlation between the Stokes shift and the orientation polarizability proved to be the less applicable to our fluorophores, as it can be seen on the plots in the Supporting Information.

The Kamlet-Taft theory provides a more suitable model, since it takes not only solvent polarity into consideration, but the acidity, basicity and polarity/polarizability of the solvent, by a multiparameter equation, giving more efficient quantitative treatment of solvent effects. However the most recent Catalán model considers the dipolarity and polarizability as two separate parameters (Equation 7.). Applying the Catalán model a better regression can be obtained in some cases, than with the Kamlet-Taft model.

$$
\mathrm{Y}=\mathrm{Y}_{\mathrm{o}}+\mathrm{aSA}+\mathrm{bSB}+\mathrm{sSP}+\mathrm{tSdP}
$$

where $\mathrm{Y}_{0}$ is the property of the substance of interest (emission maximum, Stokes shift, and so on) in the absence of solvent, for example, in the gas phase. SA is the quantitative empirical measure of the ability of bulk solvent to act as a hydrogen-bond donor towards a solute. $S B$ is the quantitative empirical measure of the ability of a bulk solvent to act as a hydrogen-bond acceptor or electron-pair donor towards a solute, forming a solute-to-solvent hydrogen bond or a solvent-to-solute coordinative bond, respectively. SP and SdP are the solvent polarizability and dipolarity parameters, respectively, determined using reference dye molecules. $a, b, s$ and $t$ are the corresponding coefficients and their inclusion in the equation indicates the dependence of the property under investigation upon the respective solvent parameter.

By applying Equation 7 for the emission wavenumber at the maximum $\left(\bar{v}_{\mathrm{em}, \max }\right)$ and the Stokes shifts $(\Delta \bar{v})$ and by using the corresponding SA, SB, SP and SdP values of the solvents (these values used in this study are given in the Supporting Information), the Catalán coefficients for $\bar{v}_{\text {em,max }}$ and $\Delta \bar{v}$ can be obtained by multilinear regression analysis. The values of the coefficients obtained by multiregression analysis are summarized in Table 2. For better visualization, the measured values of $\bar{v}_{\mathrm{em}, \max }$ and $\Delta \bar{v}$ of ICAB are plotted in Figure 4 as a function of their corresponding values calculated by Equation 7. The corresponding plots of the methylated compounds are presented in the Supporting Information. 

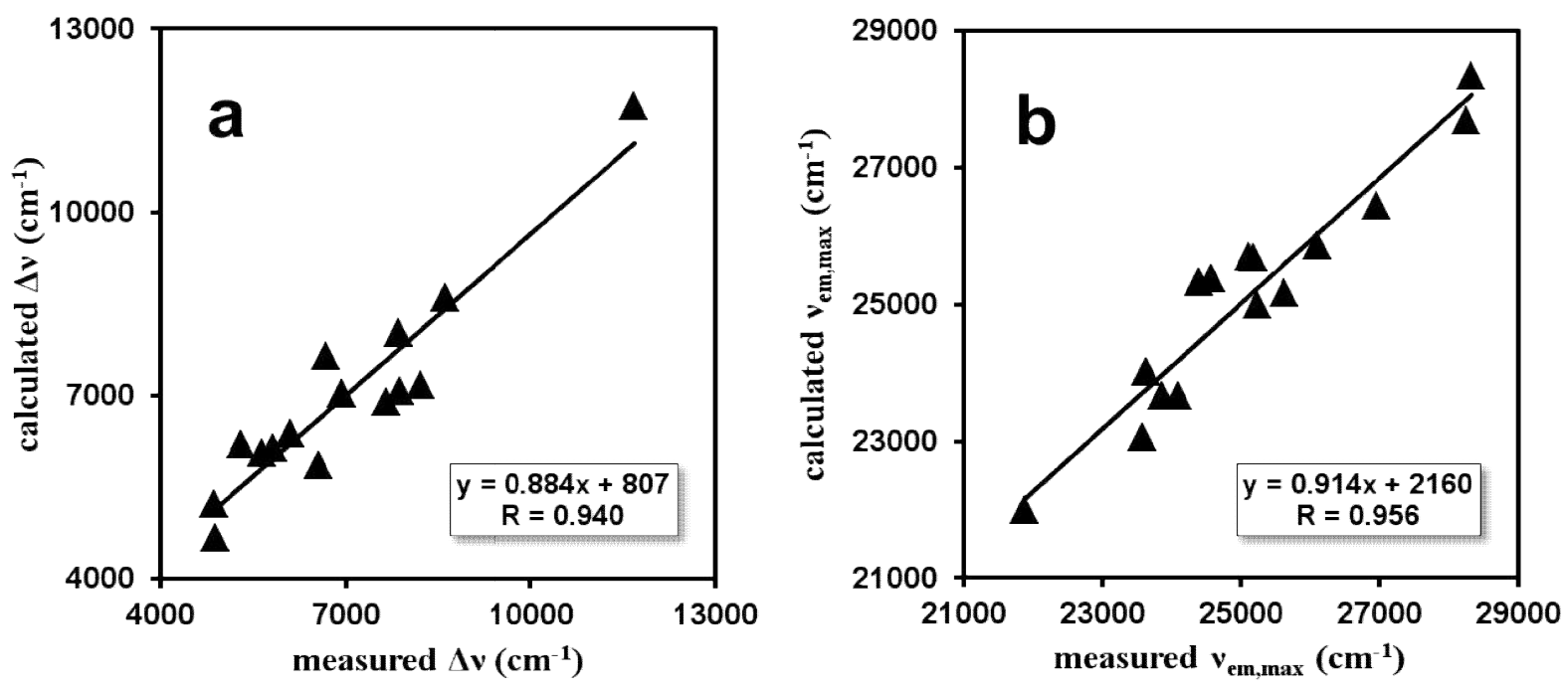

Figure 4. Plots of the measured and calculated emission maxima (a) and Stokes shift (b) for ICAB obtained by the Catalán equation

Table 2. Solvent-independent correlation coefficients $b_{\mathrm{SA}}, \mathrm{c}_{\mathrm{SB}}, \mathrm{d}_{\mathrm{SP}}$ and $\mathrm{e}_{\mathrm{SdP}}$ of the Catalán parameters SA, SB, SP and SdP, respectively, solute property of the reference system $(\bar{v}$ em,max $)_{0}$, correlation coefficient ( $\mathrm{r}$ ) and number of solvents (n) calculated by multiregression analysis for the solvatochromism of compounds 2,3 and 4 . The values were taken from ref.

[24]

\begin{tabular}{c|ccccc|c|c} 
& $\left(\begin{array}{c}\text { em,max })_{\mathbf{0}} \\
\text { Comp. }\end{array}\right.$ & $\mathbf{a}_{\mathbf{S A}}$ & $\begin{array}{c}\mathbf{b}_{\text {SB }} \\
\left(\mathbf{c m}^{-1}\right)\end{array}$ & $\mathbf{S}_{\mathbf{S P}}$ & $\mathbf{t}_{\mathbf{S d P}}$ & $\mathbf{r}$ & $\mathbf{n}$ \\
\hline $\mathbf{2}$ & $35059 \pm 1591$ & $-3257 \pm 807$ & $-1959 \pm 985$ & $-6256 \pm 2178$ & $-5316 \pm 1748$ & 0.956 & 15 \\
$\mathbf{3}$ & $33345 \pm 1567$ & $-2361 \pm 795$ & $-1545 \pm 970$ & $-5271 \pm 2145$ & $-5216 \pm 1722$ & 0.943 & 15 \\
$\mathbf{4}$ & $34790 \pm 1864$ & $-1496 \pm 945$ & $-2909 \pm 1154$ & $-7299 \pm 2551$ & $-4602 \pm 2048$ & 0.927 & 15 \\
\hline
\end{tabular}

As seen in Figure 4 and Table 2 a good correlation between the measured and the calculated values were found. All regression coefficients of the fitted lines were above 0.92 and no cross-correlation between the fitted parameters were found.

Very similar results were obtained using the Kamlet-Taft theory, as it can be seen in the Supporting Information. 


\subsection{Fluorescence quenching with pyridine}

In addition to detect local polarity, the fluorescence quenching properties of a fluorophore greatly affect its practical applicability for example in protein conformation investigation. Fluorescence quenching offers an easy to perform nondestructible method in protein characterization which requires only a small sample. We demonstrated in our previous paper, that amino-isocyanonaphthalenes (ICANs) with free N-H hydrogens do not show the same behavior as other aromatic amines extensively studied by Mataga and coworkers [25,26]. While the latter compounds show strong fluorescence quenching in the presence of pyridine the fluorescence of our ICAN derivatives only decreases at low pyridine concentrations, while in pure pyridine they become fluorescent again. This unique quenching process is the consequence of the formation of a fluorescent $\pi$-stacked complex with pyridine the amount of which will increase with pyridine concentration [27]. We wanted to know whether the ICAB derivatives also show unique quenching or they behave like the majority of aromatic amines. Therefore fluorescence titration experiments were carried out in cyclohexane-pyridine mixtures.

The results are presented in Figure 5.

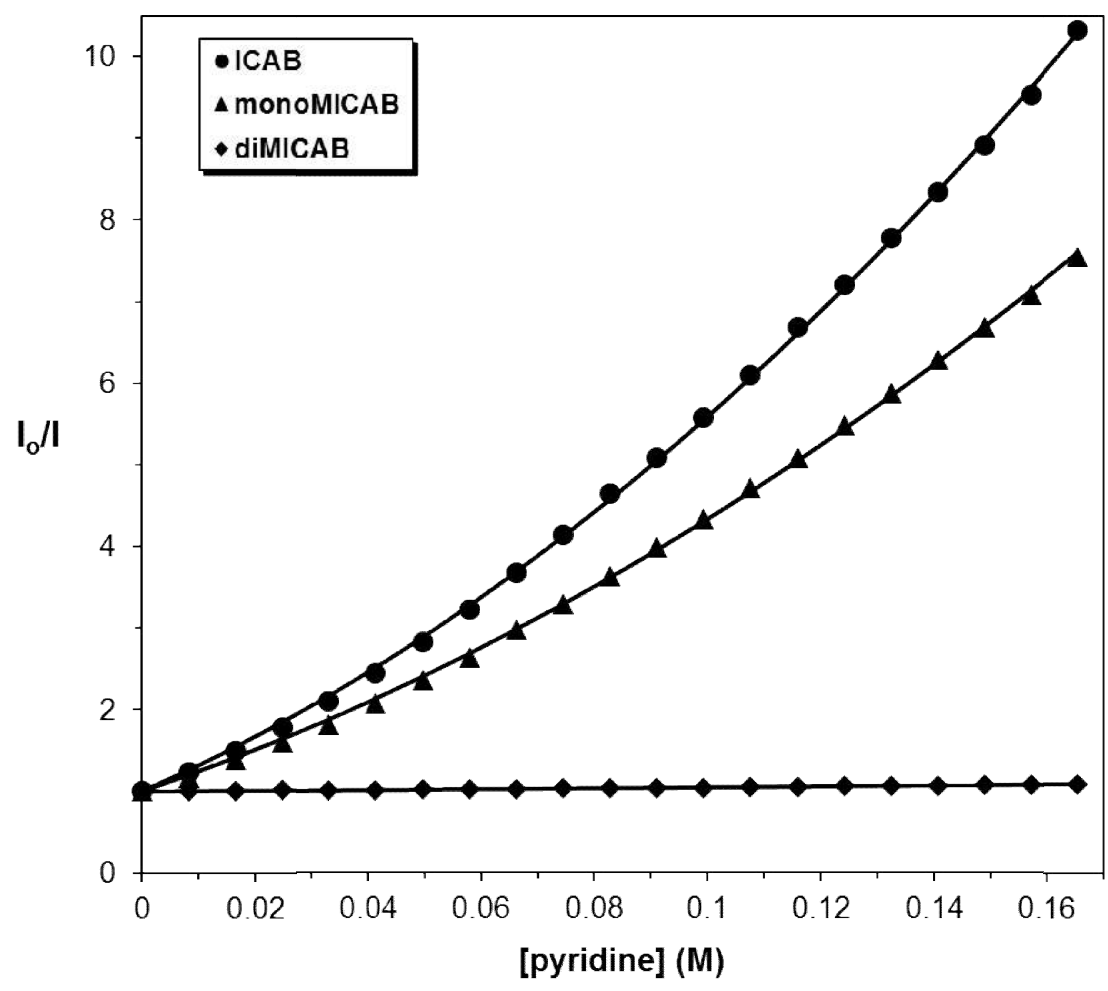

Figure 5. Stern-Volmer plots for ICAB $(\bullet)$, monoMICAB $(\boldsymbol{\Delta})$ and diMICAB $(\bullet)$ using pyridine as a quencher. $\left(20^{\circ} \mathrm{C}\right.$, cyclohexane, $\left.\mathrm{c}=3.43 \times 10^{-6} \mathrm{M}\right)$ 
As can be seen in Figure 5 the fluorescence intensity of ICAB and monoMICAB dropped to $1 / 10$ th of the original while that of diMICAB remained virtually unchanged in the presence of small amounts of pyridine. The Stern Volmer plots of ICAB and monoMICAB reveal an upward curvature which may be characteristic for simultaneous static and dynamic quenching. This simultaneous quenching process can be described by equation 8 .

$$
\frac{\mathrm{I}_{\mathrm{o}}}{\mathrm{I}}=\left(1+\mathrm{K}_{\mathrm{SV}}[\mathrm{Pyr}]\right) \cdot\left(1+\mathrm{K}_{\mathrm{a}}[\mathrm{Pyr}]\right)
$$

where $\mathrm{I}$ is the fluorescence intensity in the presence, $\mathrm{I}_{\mathrm{o}}$ in the absence of pyridine, $\mathrm{K}_{\mathrm{sv}}$ is the Stern-Volmer constant for dynamic (collision) quenching, $\mathrm{K}_{\mathrm{a}}$ is the formation constant of a ground state hydrogen-bonded pyridine complex and [Pyr] is pyridine concentration in $\mathrm{M}$.

Table 3. The Stern-Volmer constants $\mathrm{K}_{\mathrm{sv}}$ and formation constants $\mathrm{K}_{\mathrm{a}}$ of ground state $\mathrm{HB}$ pyridine complexes for the quenching of ICAB and monoMICAB. ${ }^{a}$ determined by parameter fitting using eq. $8 .{ }^{\mathrm{b}}$ determined using UV-vis titration.

\begin{tabular}{cccc}
\hline \hline & $\begin{array}{c}\mathrm{K}_{\mathrm{SV}} \\
\left(\mathrm{M}^{-1}\right)^{\mathbf{a}}\end{array}$ & $\begin{array}{c}\mathrm{K}_{\mathrm{a}} \\
\left(\mathrm{M}^{-1}\right)^{\mathbf{a}}\end{array}$ & $\begin{array}{c}\mathrm{K}_{\mathrm{a}} \\
\left(\mathrm{M}^{-1}\right)^{\mathbf{b}}\end{array}$ \\
\hline \hline ICAB & $23.8 \pm 0.9$ & $6.5 \pm 0.4$ & $2 \pm 1$ \\
monoMICAB & $18.0 \pm 0.7$ & $5.5 \pm 0.4$ & $1 \pm 1$ \\
\hline
\end{tabular}

The equilibrium constants of equation 8 were determined by parameter fitting on the curves of Figure 5 and are listed in Table 3. A very good agreement between the calculated and experimental data can be observed. The constants could be obtained with a relatively low error and their value turned out to be independent on the initial values used for parameter fitting. The $\mathrm{K}_{\mathrm{a}}$ values were also determined from the data of $\mathrm{UV}$-vis titrations with pyridine as is demonstrated in detail in the Supporting Information. It is clear from the data of Table 3 that ICAB has higher constants for both dynamic and static quenching $\left(\mathrm{K}_{\mathrm{SV}}=23.8 \pm 0.9 \mathrm{M}^{-1}\right.$ and $\left.\mathrm{K}_{\mathrm{a}}=6.5 \pm 0.4 \mathrm{M}^{-1}\right)$ compared to those of monoMICAB $\left(\mathrm{K}_{\mathrm{SV}}=18.0 \pm 0.7 \mathrm{M}^{-1}\right.$ and $\left.\mathrm{K}_{\mathrm{a}}=5.5 \pm 0.4 \mathrm{M}^{-1}\right)$. It is not surprising considering the central role of the NH hydrogen in the quenching process. ICAB has two free NH hydrogens, while monoMICAB only one, therefore the probability for the interaction between ICAB and pyridine is higher than in the case of monoMICAB. 


\subsection{Quantum Chemical Calculations}

Density Functional Theory was employed to calculate the structures, dipole moments and electronic spectra of the fluorophores in both their ground (GS) and the first excited (ES) states. The obtained dipole moments $\left(\mu_{\mathrm{GS}}=8.4 \mathrm{D}, \mu_{\mathrm{ES}}=19.7 \mathrm{D}\right)$ were higher than in the case of the previously studied naphthalene derivatives $\left(\mu_{\mathrm{GS}}=8.23 \mathrm{D}, \mu_{\mathrm{ES}}=14.96 \mathrm{D}\right.$ for ICAN), as expected.
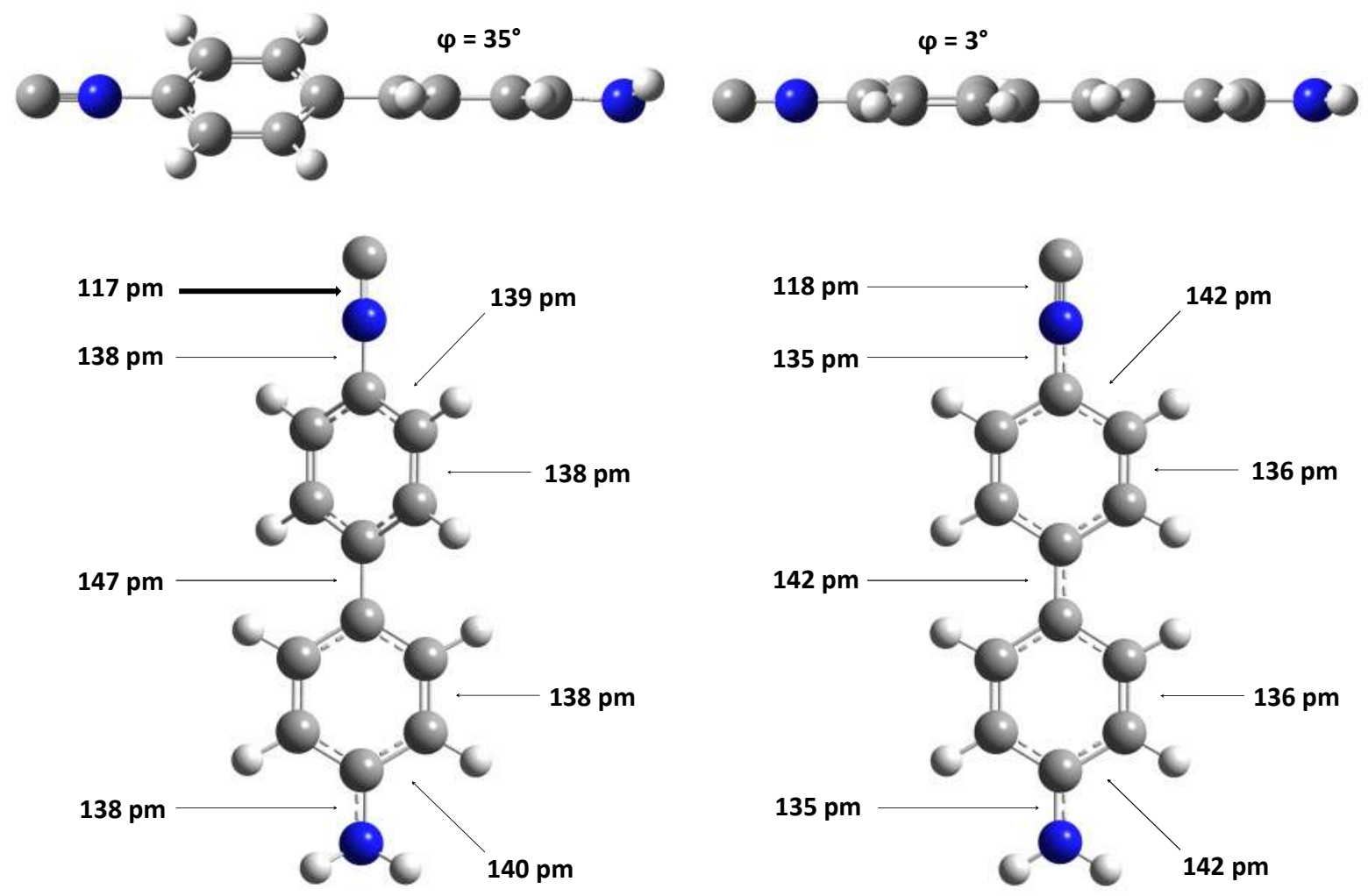

Figure 6. Calculated structural parameters for ICAB in the ground (left) and in the first excited state (right)

It is clearly visible in Figure 6, that the GS of ICAB have a twisted structure characteristic of biphenyl systems with a relatively large dihedral angle $\left(\varphi=35^{\circ}\right.$ for ICAB). This effect decreases the delocalization between the two aromatic rings. In the excited state the molecule becomes planar which is accompanied by a change in the bond lengths. This contraction along the symmetry axis of the molecule means that the coupling between two $\pi$ systems (the two substituted rings) is stronger.

The structures of monoMICAB and diMICAB are similar to ICAB: dihedral angles in both the GS and ES become slightly lower while the bond lengths are almost the same. The better solvatochromic behavior of the methylated derivates can be explained by its better electron 
donating ability due to better charge separation. It is further supported by the fluorescence spectra calculated in DMSO (Figure 7), where the position of the maxima are in very good agreement with the measured ones, $424 \mathrm{~nm}$ for ICAB, $436 \mathrm{~nm}$ for monoMICAB and $447 \mathrm{~nm}$ for diMICAB.

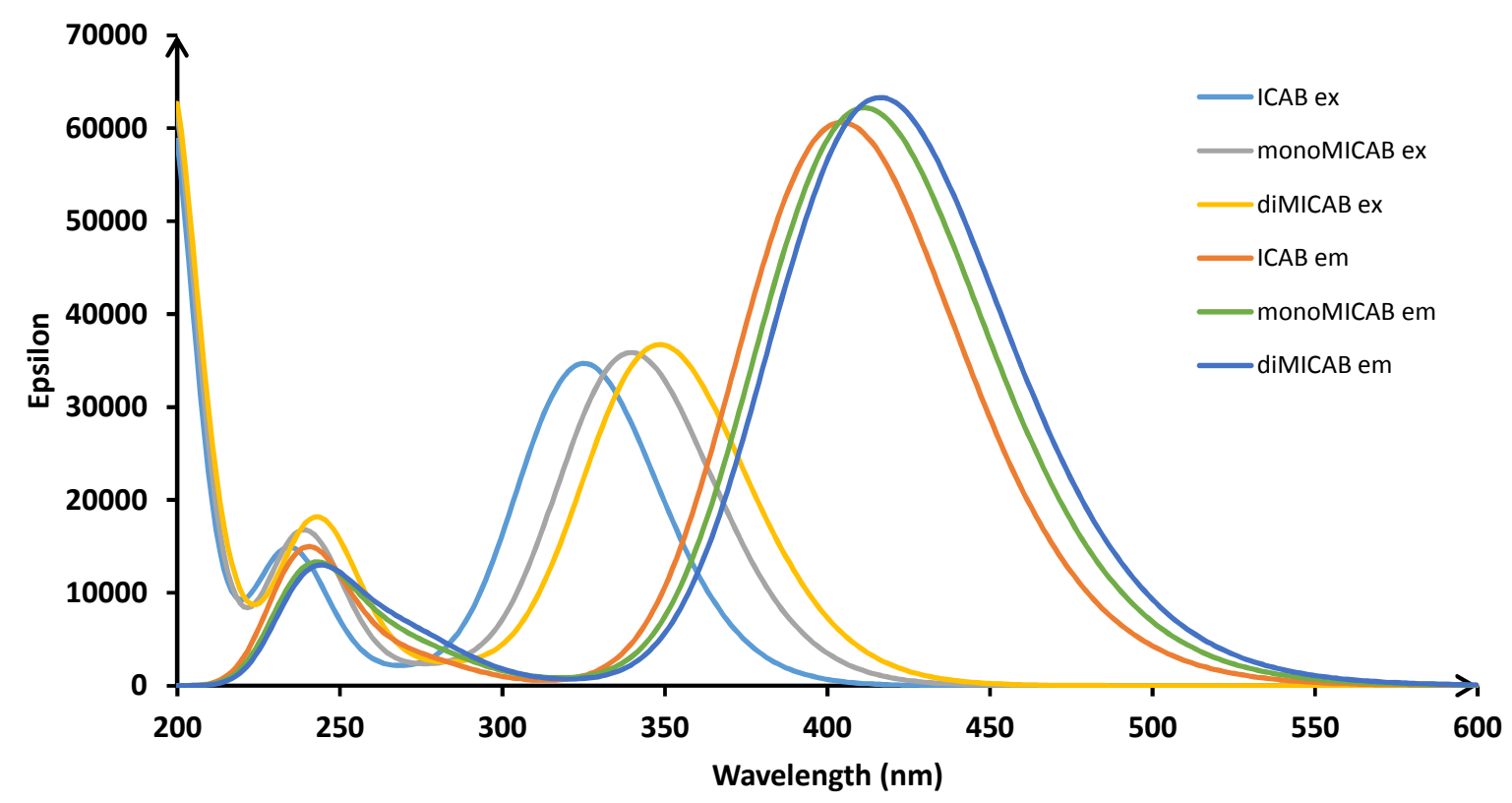

Figure 7. Calculated (M06/TZVP) UV-Vis absorption (ex) and emission (em) spectra of the ICAB derivates in DMSO.

The error is probably due to "polarized medium" approach of the software used, which considers only the polarity of the solvent, but not the specific solute-solvent interactions.

\subsection{BSA labeling}

One of the most important practical applications of solvatochromic dyes is the labeling of biomolecules to make them traceable by for example fluorescence microscopy. Since the fluorescence of our ICAB derivatives is almost completely quenched in water $\left(\phi_{\mathrm{F}} \sim 0.9-1.6 \%\right)$ and they show intense fluorescence in nonpolar solvents, a significant increase in luminosity is expected when they noncovalently bind to the hydrophobic domains of a lipid and/or protein molecule. For the experiments bovine serum albumin (BSA) was selected since it is extensively used as model compound for protein labeling. To study the applicability of our dyes in biolabeling $10 \mu \mathrm{L}$ acetonitrile stock solution $(0.20 \mathrm{mg} / \mathrm{mL})$ of the ICAB derivatives were added to $3 \mathrm{~mL}$ aqueous BSA solutions in the concentration range of $\left(3.43 \times 10^{-6}-3.43 \times 10^{-}\right.$ ${ }^{5} \mathrm{M}$ ), where the BSA concentration was increased in 10 equal steps. The spectral changes 
occurred after mixing our fluorophores with BSA are summarized in Table 4 and in the case of diMICAB in Figure 8.

Table 4. Wavelengths of maximal excitation $\lambda_{\max }(\mathrm{ex})$ and emission $\lambda_{\max }(\mathrm{em})$ in the absence and in presence of BSA, the jump in intensity and binding constants for the ICAB derivatives for their complexation with BSA. The intensity increase is given relative to the pure aqueous solutions of the dyes. ${ }^{a}$ For the determination of the binding constants the wavelengths at maximum intensities $\lambda_{\max }(\mathrm{em})(\mathrm{BSA})$ were used.

\begin{tabular}{|l|c|c|c|c|c|c|c|}
\hline & $\begin{array}{c}\lambda_{\max }(\mathrm{em}) \\
\left(\mathrm{H}_{2} \mathrm{O}\right) \\
(\mathrm{nm})\end{array}$ & $\begin{array}{c}\lambda_{\max }(\mathrm{em}) \\
(\mathrm{BSA}) \\
(\mathrm{nm})\end{array}$ & $\begin{array}{c}\lambda_{\max }(\mathrm{ex}) \\
\left(\mathrm{H}_{2} \mathrm{O}\right) \\
(\mathrm{nm})\end{array}$ & $\begin{array}{c}\lambda_{\max }(\mathrm{ex}) \\
(\mathrm{BSA}) \\
(\mathrm{nm})\end{array}$ & $\begin{array}{c}\text { Intensity } \\
\text { increase } \\
(1 \text { eq. } \\
\text { BSA })\end{array}$ & $\begin{array}{c}\text { Intensity } \\
\text { increase } \\
(10 \text { eq. } \\
\text { BSA })\end{array}$ & $\mathrm{K}^{\mathrm{a}}\left(\mathrm{M}^{-1}\right)$ \\
\hline ICAB & 457 & 405 & 298 & 314 & 13 & 70 & $3.8 \times 10^{4} \pm 5.7 \times 10^{3}$ \\
\hline monoMICAB & 458 & 409 & 305 & 335 & 43 & 170 & $6.0 \times 10^{4} \pm 3.9 \times 10^{3}$ \\
\hline diMICAB & 417 & 409 & 315 & 347 & 32 & 188 & $2.3 \times 10^{4} \pm 3.2 \times 10^{3}$ \\
\hline
\end{tabular}

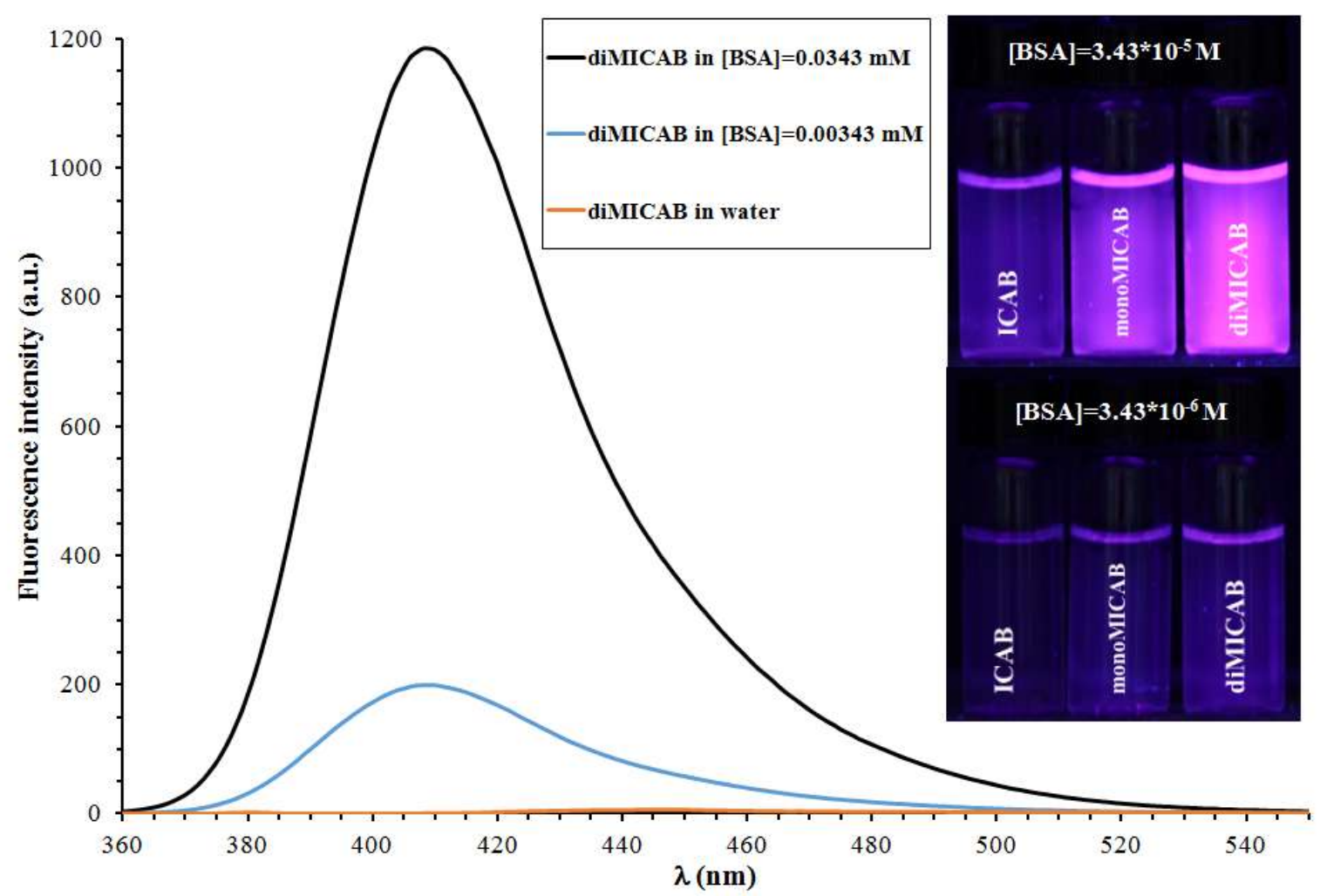

Figure 8. A demonstration of the spectral changes following the complexation of diMICAB with BSA in water. The photographs show the aqueous solutions of ICAB derivatives illuminated by $\lambda=365 \mathrm{~nm}$ UV-light after the addition of BSA. $\left([\mathrm{ICAB}]=3.43 \times 10^{-6} \mathrm{M},[\right.$ monoMICAB $\left.]=3.20 \times 10^{-6} \mathrm{M},[\mathrm{diMICAB}]=3.00 \times 10^{-6} \mathrm{M}, 2{ }^{\circ} \mathrm{C}\right)$ 
An immediate increase in the fluorescence intensity was observed in each case even in the most dilute BSA solutions. The intensity further increased upon increasing the amount of BSA and an approximately 190 fold increase in the case of diMICAB could be observed where the molar ratio of the fluorophore and the BSA was $\sim 1: 10$. The spectral changes in time were also monitored; the jump in intensity appeared instantly after mixing the dye with BSA and only a few percent decrease within 5 minutes at $25{ }^{\circ} \mathrm{C}$ could be observed. After that, the spectra of the complexes remained unchanged for at least 24 hours. We assume that the instantaneous characteristic of the reaction excludes the post-adsorption conformational changes, a direct probe-surface contact is more probable. This probe-surface contact was also followed by a considerable blue shift of the emission maximum indicating a less polar environment around the fluorophores. The hypsochromic shifts were $\Delta \lambda_{\max , \mathrm{em}}=52 \mathrm{~nm}, 49 \mathrm{~nm}$ and $8 \mathrm{~nm}$ for ICAB, monoMICAB and diMICAB, respectively. An inverse effect for the excitation maxima for the complexed dyes could be observed, however to a lesser extent and in a reversed order when compared to the changes in emission. Namely the bathochromic shifts measured for ICAB, monoMICAB and diMICAB were $\Delta \lambda_{\text {max,ex }}=16 \mathrm{~nm}, 30 \mathrm{~nm}$ and 32 $\mathrm{nm}$, respectively. It should be noted that the excitation bands of the complexed fluorophores separate largely from that of the uncomplexed BSA. Using these excitation maxima no fluorescence signal of the BSA could be observed as can be seen on the titration spectra presented in the Supporting Information as Figures S9-11. The binding constants for the probe-BSA complexes were determined by data fitting on the fluorescence intensity versus BSA concentration curve. The fitted curves along with the experimental plots are presented in Figure 9a. Eq. 5. was derived assuming 1:1 complexation between the probe and BSA and based on the very good fit of the calculated curves the formation of other complex species in considerable amount can be excluded. This assumption was further supported by the linearization of eq. 5 as presented in Figure 9b. In each case the experimental data could be fit linearly resulting parameters in very good agreement with the calculated ones. The binding constant determined fluorometrically were $\mathrm{K}_{\mathrm{ICAB}-\mathrm{BSA}}=3.8 \times 10^{4} \pm 5.7 \times 10^{3} \mathrm{M}^{-1}, \mathrm{~K}_{\text {monoMICAB- }}$ $\mathrm{BSA}=6.0 \times 10^{4} \pm 3.9 \times 10^{3} \mathrm{M}^{-1}$ and $\mathrm{K}_{\text {diMICAB-BSA }}=2.3 \times 10^{4} \pm 3.2 \times 10^{3} \mathrm{M}^{-1}$. These constants are in the order of the ones determined in previous studies for 6-propionyl-2-( $N, N$ dimethylamino)naphthalene (PRODAN) and 1-(anilino)naphthalene-8-sulfonate (ANS) [11]. 

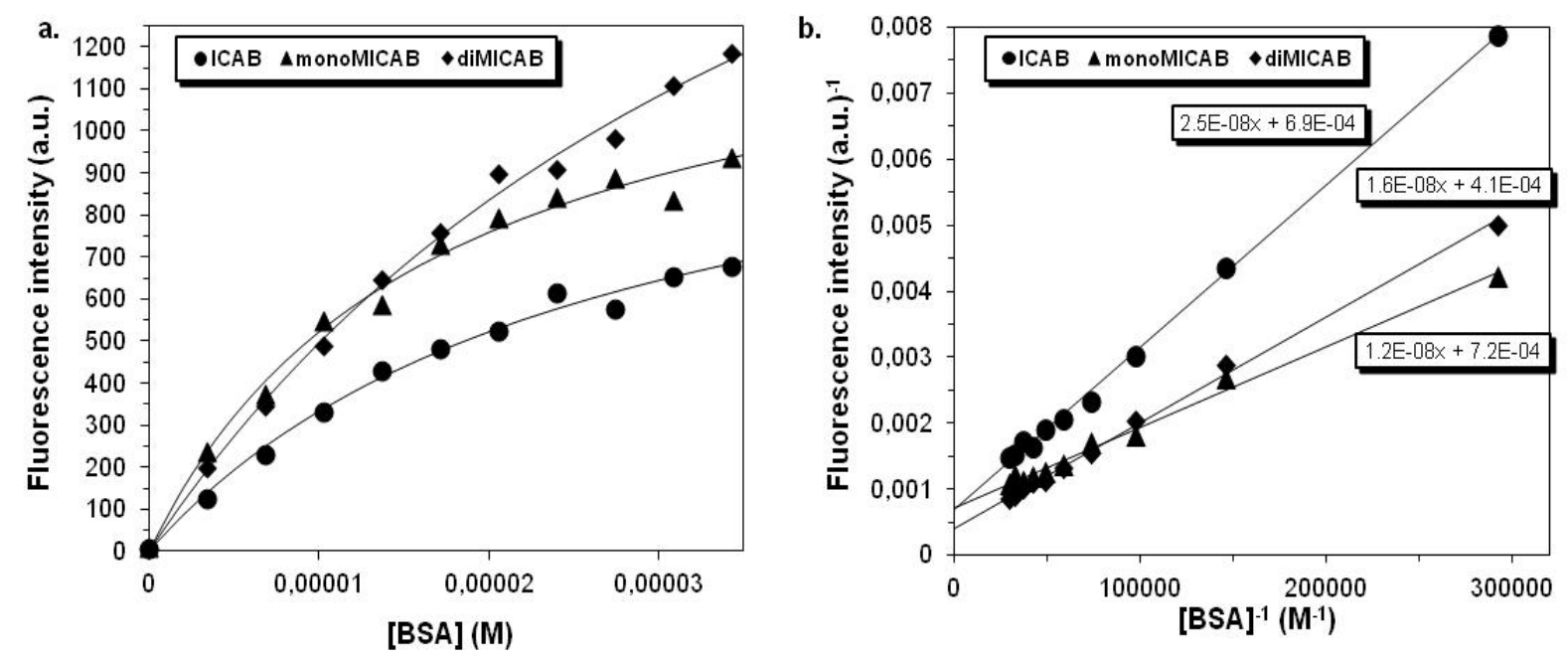

Figure 9. (a) Variation in relative fluorescence intensity of $\operatorname{ICAB}\left(3.43 \times 10^{-6} \mathrm{M}\right)$, monoMICAB $\left(3.20 \times 10^{-6} \mathrm{M}\right)$ and diMICAB $\left(3.00 \times 10^{-6} \mathrm{M}\right)$ with concentration of BSA in the range $3.43 \times 10^{-6}$ to $3.43 \times 10^{-5} \mathrm{M}$ in water at $25^{\circ} \mathrm{C}$. Excitation wavelengths were $314 \mathrm{~nm}, 335 \mathrm{~nm}$ and $347 \mathrm{~nm}$ respectively. The solid curve represents the best fit of the data using eq. 5. (b) linearization of eq. 5.

To get a deeper insight into the nature of the complexation of ICAB derivatives with BSA, time-resolved fluorescence lifetime measurements were carried out for all ICAB derivatives in the presence and absence of BSA in water. $3 \mu \mathrm{M}$ samples of the fluorophores were excited at $355 \mathrm{~nm}$ and the emission intensity was collected between 370 and $500 \mathrm{~nm}$ with a resolution of $10 \mathrm{~nm}$. The experiments were repeated in acetonitrile and ethyl acetate with the uncomplexed fluorophores. These organic solvents were selected to simulate the environment of the complexed dyes inside BSA and were selected based on the emission maximum obtained by steady state fluorescence measurements. For example the emission maximum of ICAB, monoMICAB and diMICAB were $397 \mathrm{~nm}, 403 \mathrm{~nm}$ and $406 \mathrm{~nm}$ in ethyl acetate, while the corresponding values were $405 \mathrm{~nm}, 409 \mathrm{~nm}$ and $409 \mathrm{~nm}$ in the presence of BSA. Fluorescence decay for the BSA complexes and the pure fluorophores in organic solvents could be fitted to single exponential functions. It should be noted, however, that the lifetimes in pure water could not be determined due to instrumental parameters. They turned out to be significantly smaller than the length of the laser impulse used for excitation.

The lifetimes $(\tau)$ of the excited states in different solvents and in aqueous BSA solutions are listed in Table 5. 
Table 5. The lifetimes of the excited states $(\tau)$ determined as the reciprocal of the decay rates $(\mathrm{k})$ in different media. *The lifetimes in water were too short to be determined using the current instrumental setup. The error in the measurements of $\tau$ values were within $\pm 10 \%$.

\begin{tabular}{|l|c|c|c|}
\hline & \multicolumn{3}{|c|}{$\boldsymbol{\tau}(\mathbf{n s})$} \\
Solvent & ICAB & monoMICAB & diMICAB \\
\hline Water & N/A* & N/A* & N/A* \\
\hline 10 eq. BSA (aq) & 2.1 & 2.1 & 2.4 \\
\hline Ethyl acetate & 1.7 & 1.4 & 1.7 \\
\hline Acetonitrile & 2.0 & 1.8 & 1.9 \\
\hline
\end{tabular}

It is evident from the data that the lifetimes of the BSA-complexed ICAB derivatives are virtually the same and are approximately 2 ns. The increased lifetimes compared to those in pure water refer to a less polar environment around the complexed dye molecules and can be explained by the less pronounced dynamic quencing effects of the water molecules. These results are in good agreement with the ones obtained for organic solvents and are in line with the results of the steady state fluorescence experiments. The time resolved fluorescence spectra extracted from the fluorescence decay data at different times are also closely matched with the steady-state fluorescence spectrum as is presented in Figure 10 for BSA-complexed diMICAB in water, at dye:BSA molar ratio of 1:10. The spectra for the other complexed derivatives are presented in the Supporting Information as Figure S8. 


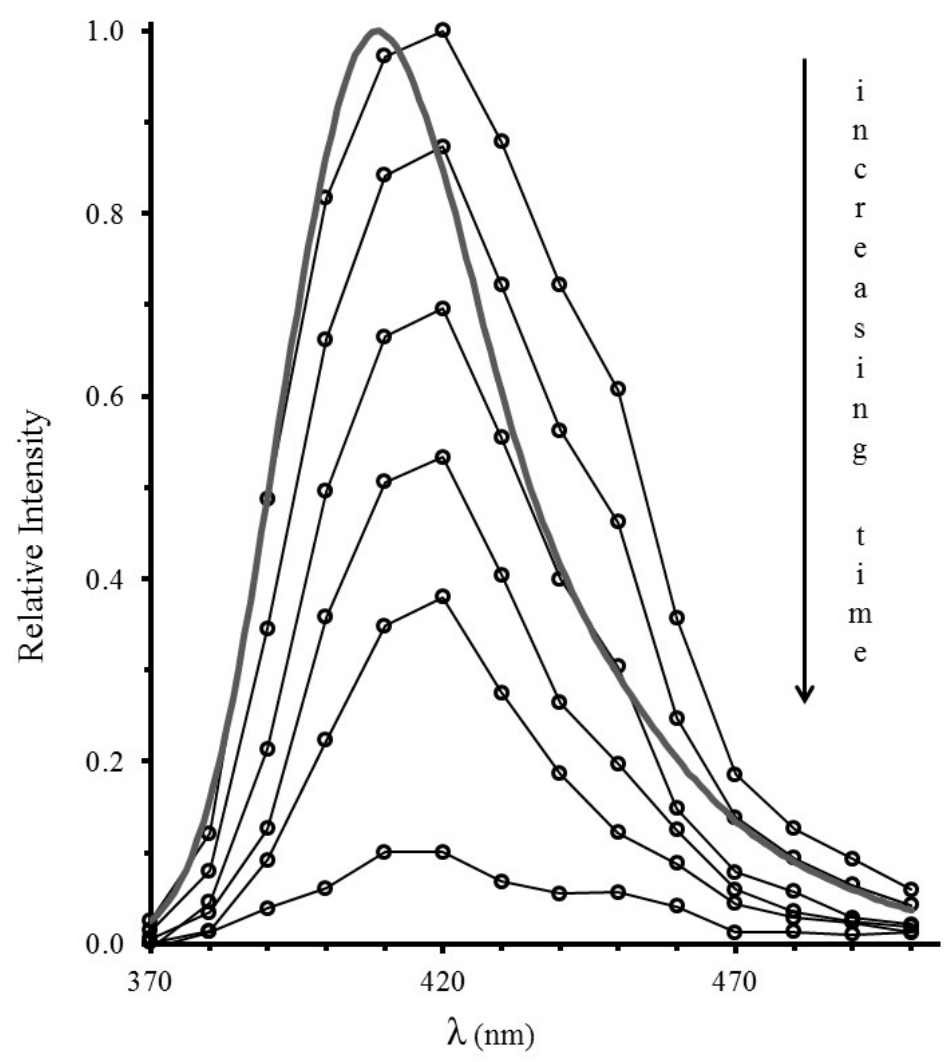

Figure 10. Time-resolved and steady-state fluorescence spectra of diMICAB $\left(3.00 \times 10^{-6}\right.$ $\mathrm{M})$ in the presence of BSA $\left(3.43 \times 10^{-5} \mathrm{M}\right)$ in water at $25^{\circ} \mathrm{C}$. Curves with circles represent the time-resolved spectra recorded at $\Delta \mathrm{t}=1.0 \mathrm{~ns}$ intervals. The solid curve represents the steady-state fluorescence spectrum.

\section{Conclusions}

4-amino-4'-isocyanobiphenyl (ICAB) and its mono-and dialkylated derivatives (monoMICAB and diMICAB) were prepared starting from the easily available benzidine. Not as the starting material benzidine, all three compounds showed enhanced positive solvatochromic properties similar to that of our previously introduced dye: 1-amino-5-isocyanonaphthalene (ICAN). The solvatochromic range were found to be $\Delta \lambda_{\max }=104 \mathrm{~nm}$ (ICAB), $92 \mathrm{~nm}$ (monoMICAB) and 90 $\mathrm{nm}$ (diMICAB), respectively. All three products showed intense fluorescence with good fluorescence quantum yields in most solvents $\left(\Phi_{\mathrm{F}}=0.88\right.$ in water to $\Phi_{\mathrm{F}}=0.89$ in acetonitrile, the highest yields were obtained in the case of the dimethyl derivative). The emission maximum for the mono- and dimethylated derivatives is located in the blue region of the visible spectrum in most solvents; however this is only true for ICAB in the most polar solvents. Fluorescent properties varying with the solvent polarity could be well described by both the Kamlet-Taft and Catalán equations. High-level DFT calculations revealed the nonplanar structures of the molecules, which is probably due to the single bond character of 
C1-C1'. The free rotation between the two aromatic rings can be the explanation for the lower emission wavelengths compared to ICAN.

Fluorescence quenching by pyridine was observed in the case of molecules having free hydrogens on the amino group. Their Stern-Volmer quenching plots exhibited an upward curvature which is characteristic for simultaneous static and dynamic quenching. The SternVolmer constants and the formation constants of the ground state pyridine complexes were determined by multilinear regression analysis. ICAB has higher constants for both dynamic and static quenching $\left(\mathrm{K}_{\mathrm{SV}}=23.8 \pm 0.86 \quad \mathrm{M}^{-1}\right.$ and $\left.\mathrm{K}_{\mathrm{a}}=6.55 \pm 0.39 \quad \mathrm{M}^{-1}\right)$ compared to those of monoMICAB $\left(\mathrm{K}_{\mathrm{SV}}=18.0 \pm 0.74 \mathrm{M}^{-1}\right.$ and $\left.\mathrm{K}_{\mathrm{a}}=5.51 \pm 0.38 \mathrm{M}^{-1}\right)$.

The practical applicability of all three compounds in the field of biolabeling was demonstrated by their complexation with bovine serum albumin (BSA). Since their fluorescence is almost completely quenched by water, even on the addition of small amounts of BSA resulted in up to $190 \mathrm{x}$ increase in their fluorescence intensity. In addition, the increase in luminosity was accompanied by a blue-shift of their emission maximum, $\Delta \lambda_{\max }=52 \mathrm{~nm}, 49 \mathrm{~nm}$ and $8 \mathrm{~nm}$ for $\mathrm{ICAB}$, monoMICAB and diMICAB, respectively. The binding constants for the BSAfluorophore complexes were determined fluorometrically and were found to be $\mathrm{K}_{\mathrm{ICAB}}$ $\mathrm{BSA}=3.8 \times 10^{4} \pm 5.7 \times 10^{3} \quad \mathrm{M}^{-1}, \quad \mathrm{~K}_{\text {monoMICAB-BSA }}=6.0 \times 10^{4} \pm 3.9 \times 10^{3} \quad \mathrm{M}^{-1}$ and $\mathrm{K}_{\text {diMICAB- }}$ $\mathrm{BSA}=2.3 \times 10^{4} \pm 3.2 \times 10^{3} \mathrm{M}^{-1}$.

Time resolved fluorescence measurements showed an increased lifetime for ICAB derivatives dissolved in aqueous BSA compared to those of in pure water. The BSA-complexed lifetimes were approximately $2 \mathrm{~ns}$ for all the 3 ICABs and were found to be very close to those of recorded in organic solvents (acetonitrile, ethyl acetate) used for modeling the local environment of the bound dyes in BSA.

\section{Acknowledgment}

This work was financially supported by the grant K-116465 given by OTKA (National Found for Scientific Research Development, Hungary), and the grant TÁMOP-4.2.2.A-11/1/KONV2012-0036 by the European Union. This work was partially supported by the European Union and the European Social Fund through project Supercomputer, the National Virtual Lab, grant no.: TÁMOP-4.2.2.C-11/1/KONV-2012-0010. The authors also would like to express their thanks to Mr. Tamás Ditrói for his assistance in Laser Flash Photolysis experiments. 


\section{References}

1. R.M. Epand, R. Kraayenhof, Chem. Phys. Lipids 101 (1999) 57-64.

2. L.D. Lavis, R.T. Raines, ACS Chem.Biol. 3 (2008) 142-155.

3. G.S. Loving, M.Sainlos, B. Imperiali, Trends in Biotechnology 28 (2009) 73-83.

4. V. Ntziachristos, Annu. Rev. Biomed. Eng. 8 (2006) 1-33.

5. Y. Pu, R. Tang, J. Xue, W.B. Wang, B. Xu, S. Achilefu, AppliedOptics 53 (2014) $2345-2351$.

6. C.N. Ho, G. Patonay, I.M. Warner, Trends in Analytical Chemistry 5 (1986) 37-43.

7. G. Hild, M. Nyitrai, R. Gharavi, B. Somogyi, J. Belágyi, J. Photochem. Photobiol. B: Biol. 35 (1996) 175-179.

8. G. Weber, F.J. Farris, Biochemistry 18 (1979) 3075-3078.

9. O.A. Kucherak, P. Didier, Y. Mély, A.S. Klymchenko, J. Phys. Chem. Lett. 1 (2010) $616-620$.

10. E.L. Gelamo, M. Tabak, Spectrochim. Acta A 56 (2000) 2255-2271.

11. C.A. Haskard, E.C.Y. Li-Chan, J. Agric. Food Chem. 46 (1998) 2671-2677.

12. F. Moreno, M. Cortijo, J. Gonzalez-Jimenez, Photochem. Photobiol. 70 (1999) 695700.

13. F. Kulwinder, J.D. Brennan, G.A. Baker, M.A. Doody, F.V. Bright, Biophys. J. 75 (1998) 1084-1096.

14. D. Rácz, M. Nagy, A. Mándi, M. Zsuga, S.Kéki, J. Photoch. Photobio. A 270 (2013) $19-27$.

15. Y. Bard, Nonlinear Parameter Estimation; Academic Press, New York, 1974, p.341.

16. Y. Zhao, D.G. Truhlar, Theor. Chem. Acc. 120 (2008) 215-241.

17. W.J. Hehre, R. Ditchfield, J.A.Pople, J. Chem. Phys. 56 (1972) 2257.

18. J. Tomasi, B. Mennucci, R.Cammi, Chem. Rev. 105 (2005) 2999-3093.

19. G. Scalmani, M.J. Frisch, J. Chem. Phys. 11 (2010) 114-110.

20. J. Tomasi, B. Mennucci, E.Cances, THEOCHEM 464 (1999) 211.

21. J.L. Pascual-Ahuir, E. Silla, I. Tunon, J. Comput. Chem. 15 (1994) 1127-1138.

22. M.J. Frisch, G.W. Trucks, H.B. Schlegel, G.E. Scuseria, M.A. Robb, J.R. Cheeseman, G. Scalmani, V. Barone, B. Mennucci, G.A. Petersson, H. Nakatsuji, M. Caricato, X. Li, H.P. Hratchian, A.F. Izmaylov, J. Bloino, G. Zheng, J.L. Sonnenberg, M. Hada, M. Ehara, K. Toyota, R. Fukuda, J. Hasegawa, M. Ishida, T. Nakajima, Y. Honda, O. Kitao, H. Nakai, T. Vreven, J.A. Montgomery, J.E. Peralta, F. Ogliaro, M. Bearpark, J.J. Heyd, E. Brothers, K.N. Kudin, V.N. Staroverov, R. Kobayashi, J. Normand, K. 
Raghavachari, A. Rendell, J.C. Burant, S.S. Iyengar, J. Tomasi, M. Cossi, N. Rega, N.J. Millam, M. Klene, J.E. Knox, J.B. Cross, V. Bakken, C. Adamo, J. Jaramillo, R. Gomperts, R.E. Stratmann, O. Yazyev, A.J. Austin, R. Cammi, C. Pomelli, J.W. Ochterski, R.L. Martin, K. Morokuma, V.G. Zakrzewski, G.A. Voth, P. Salvador, J.J. Dannenberg, S. Dapprich, A.D. Daniels, O. Farkas, J.B. Foresman, J.V. Ortiz, J. Cioslowski, D.J. Fox, Gaussian 09, Gaussian Inc, Wallingford CT (USA), 2009.

23. N.P. Campbell, A.S. Finch, S.E. Rokita, ChemPhysChem 11 (2010) 1768-1773.

24. J.Catalán, J. Phys. Chem. B, 113 (2009) 5951-5960.

25. N. Ikeda, T. Okada, N. Mataga, Bull. Chem. Soc. Jpn. 54 (1981) 1025-1030.

26. N. Ikeda, H. Miyasaka, T. Okada, N. Mataga, J. Am. Chem. Soc. 105 (1983) 52065211.

27. M. Nagy, D. Rácz, L. Lázár, M. Purgel, T. Ditrói, M. Zsuga, S. Kéki, ChemPhysChem 15 (2014) 3614-3625. 